\title{
'Sometimes the simplest interventions can make a big difference'
}

Please send any ideas for feature articles for consideration to:

Ruth Doherty,

Managing Editor,

British Dental Journal

The Macmillan Building,

4-6 Crinan Street,

London,

N1 9XW

Email: r.doherty@nature.com

London dentists Andrew Dawood and Susan Tanner speak to the BDJ ahead of their presentation at the 2013 British Dental Conference \&t Exhibition. The London practice owners talk about Channel 4's Embarrassing Bodies, facial reconstruction, implant inventions and more.

\section{What memories do you have of your own first trip to the dentist?}

Andrew: I don't remember much about the first visit, but I do remember that we were always given sweets by our parents for being good! Having said this, my first dentist Alan Barr, in Croydon, was technically excellent and many of his restorations are still surviving. My family eventually moved to Lawrence Levy, in London. He was another technically brilliant dentist who had a fantastic eye for detail and always strove for excellence. In many respects he led me to dentistry, and eventually, many years later, I joined his practice.

Susan: I also don't remember much of the dentist as a smaller child, but as a teenager the dentist, David Preiss in Hampstead, was inspirational. I ended up doing work experience with him...and in those days I was actually allowed to nurse chair side!

\section{What do you enjoy most about your day-to-day role in the practice?}

Andrew: I have a diverse role, interacting with our referrers, our multidisciplinary team and also with our radiological practice, Cavendish Imaging, through which we provide support for a large number of dentists locally and across the UK. However, my great passion is for implant dentistry, particularly the challenging surgery for the atrophic-jaw cases that are sent to us from all over the country. These patients are the focus of so much of what we do.

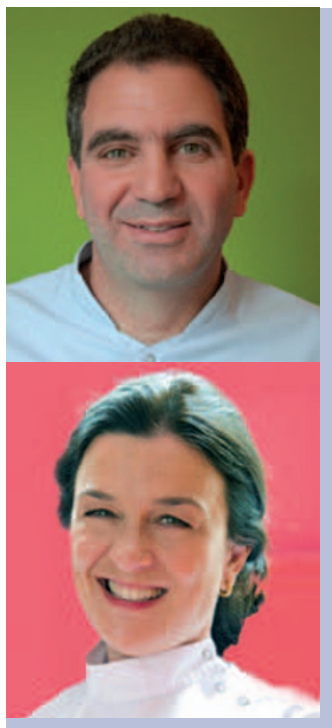

Andrew Dawood and Susan Tanner together run the Dawood and Tanner Multidisciplinary Specialist Referral Dental Practice in London's West End. The Practice aims to provide the best possible care for each and every patient, as well as up to the minute further education for colleagues. Andrew and Susan lecture regularly on surgical and prosthodontic aspects of implant dentistry in the UK and internationally and are published in the scientific literature. They also head Cavendish Imaging, an imaging and medical modelling facility where CBCT scanning, 3D printing and virtual surgical planning are used to facilitate all types of implant placements as well as complex surgical procedures.

Andrew qualified from the Royal London Hospital and obtained his Masters degree at Guy's Hospital. He devotes his time to dental implant surgery, research and development in the implant world and in 3D imaging and manufacturing. Andrew has honorary attachments to University College Hospital and the St Bartholomew's and Royal London Hospitals, working in the implant rehabilitation of patients who have undergone extensive resection or trauma. He has a number of significant innovations to his name, including the development of an award winning computerised implant drill controller and various implant designs.

Susan graduated from University College Hospital and has a Masters degree from The Eastman in prosthetics. She takes great pleasure in teaching and lecturing abroad, helping the general dental practitioner to bring the benefits of implant treatments to their patients and their working life. Within her specialist prosthodontic practice, Susan is particularly interested in the implant rehabilitation of patients who have atrophic jaws, with the goal of providing immediate fixed reconstructions, even where there is extensive resorption. She is also a trustee of the charity 'Saving Faces', The Facial Surgery Research Foundation, (www.savingfaces.co.uk) dedicated to supporting nationwide research into head and neck cancer and trauma surgery, prevention of oral diseases in the younger generation and awareness of facial disfigurement.

Susan: Patient interaction is what it's all about for me. I enjoy people and therefore I find every patient interesting. Due to the nature of the specialist dentistry I do, I spend much of my time analysing patients' faces and I get to talk to them more than usual. I particularly enjoy their individual challenging dental problems and seeing the improved quality of life following implant treatment.

Another aspect of my day-to-day role, is overseeing the management of our large practice and the care and well-being of our staff. This is very satisfying and enjoyable when it all runs smoothly!

You have created your own tooth cleaning materials - what advice do you have for dentists wishing to launch products?

Susan: I have been seeing mostly edentulous patients on a daily basis for years and this motivated me to want to make products that would encourage the general public to just brush their teeth. I had this wish for over ten years and then 
the opportunity presented itself. After two years of product development I finally had some beautiful and delicious toothpastes; but producing and retailing the products has been one of the hardest, and sometimes the most frustrating, things I have ever done. The constraints of the market, competition from the conglomerates and the enormous budgets needed to promote a new product are stifling. However the steep learning curve and overall experience has been an enjoyable diversion from routine practice.

\section{Andrew, what are the challenges facing entrepreneurial dentists in the UK?}

Being entrepreneurial is really not enough; you have to be passionate about what you do. We are fortunate to work in private practice and are therefore relatively free to practice in the patient-centred manner that we choose. Historically the British public do not expect to have to pay very much at all for their dental care and do not always prioritise their oral health, appearance, and function; however we feel that this is changing. There is a need to raise awareness and motivate our patients, and also to motivate those of our colleagues who have so little faith in their patients that they do not even offer the sort of sophisticated life-changing and practice-building treatments that they would find to be so fulfilling.

\section{You have quite an unusual web- site for your practice (www. dawoodandtanner.co.uk)! Do you have any tips for dentists wishing to develop their practice website?}

Keep it simple! With each iteration our website becomes smaller and easier to navigate. However more and more patients look at our website before coming to see us. We feel that your website should reflect the character and ethos of your practices.

\section{Susan, what are the challenges faced when giving live demonstrations of techniques?}

I might say it is the pressure! A procedure that one does so frequently that it feels as though it is a 'walk in the park' suddenly changes to a series of predetermined steps all needing verbal explanation, and of course with the premise that the patient will cooperate and the technical back-up is perfect. Everything has to go to plan. When it doesn't; well that is what a live procedure is all about: demonstrating how to solve a problem with the wellbeing of the patient uppermost in mind.

\section{Susan, you are involved in Saving Faces - why did you choose to become involved with this charity?}

I worked with Professor Iain Hutchison, Saving Faces founder, at Bart's. Iain's vision and boundless enthusiasm is infectious. The charity is 'dedicated to the worldwide reduction of facial injuries and diseases and takes the lead in education and research to improve the physical and psychological treatment of all victims of oral cancer and other facial diseases' - a worthy objective. The Saving Faces Diagnostic Advice Service (SFDADS) is an example of the kind of fantastic work that the charity does to improve GDP education and the early detection of oral cancer.

\section{What is the biggest challenge in treating patients requiring facial reconstruction?}

Susan: The prosthodontist must have empathy with the patient and also a positive, reassuring attitude. I want the patient to know that I will do everything possible to help improve their quality of life. Every patient that we see after resective or reconstructive surgery has different challenges that may have an obvious prosthodontic solution, but often need a more creative, multidisciplinary approach in order to achieve the best possible result. Thereafter, ongoing care and maintenance is a serious problem.

\section{Andrew, can you tell us about the implant research you are involved in?}

I am involved in a variety of different projects, among others: new implant designs. For example, we have developed 'bifunctional' implants capable of simultaneously anchoring oral and orbital or nasal prostheses, new procedures for cancer patients, such as immediate loading implants immediately placed in vascularised free-flaps, and new surgical approaches for orthopaedics where precise placement of hip-prostheses will make a huge difference to the longevity of the artificial joint. It is exciting to feed innovations in dentistry and dental materials into other spheres of medicine.

Together with the brilliant maxillofacial surgeons with whom we collaborate, we have seen a radical change in recent years in the way that our cancer patients have been reconstructed. The great joy is that experience with some of these innovative approaches to extreme 'cases' has been to the great benefit of our dayto-day patients.

Do you see dentists still placing implants in twenty years time?

Andrew: Yes certainly. But how it is done will change and adjunctive procedures such as grafting will become radically different with developments in tissue, cellular and molecular engineering.

\section{Susan, what do you feel is the most important advance in prosthodontics in the last ten years?}

New developments and protocols in implant dentistry provide the most amazing immediately loaded prosthodontic solutions for patients, even where there is advanced resorption. These developments go hand in hand with astonishing innovations in 3D technologies such as cone beam CT and CAD CAM manufacturing processes to make treatments so much more straightforward for the patient and the referring dentist.

\section{What is the biggest challenge in treating patients requiring facial reconstruction?}

Andrew: Teamwork is always important, and never more so than working in this discipline. To really achieve a fantastic result at the end of the day requires extended multidisciplinary planning and coordination and the entire team to pull together. The ongoing role of the general dental practitioner is often overlooked and it is essential.

Susan: If everyone pulls together then at least some of these patients will benefit from being immediately and comprehensively reconstructed with preplanned ideally placed grafts and implant 
restorations, allowing smiling and eating and quite a difference in quality of life post-resective cancer surgery.

Susan, do you find it a challenge to reconcile the aesthetic sensitivities of those patients that come to you for cosmetic treatment and those you meet in your charity work?

Yes, indeed! Many patients who have undergone facial surgery are amazingly stoic and feel lucky to be alive. We have been fortunate to work with many wonderful personalities. However, some patients are obsessed by small cosmetic issues quite blown out of proportion. In both cases patients need time for explanation and reassurance. Sometimes the simplest interventions can make a big difference.

\section{Andrew, what was it like appearing on Embarrassing Bodies on Channel 4?}

I never thought I would appear in a ‘dental makeover' programme. We are generally horrified at the way that cosmetic dentistry is presented, superficially and flippantly, as something that can happen in a lunch hour, and with little regard for the lifelong consequences.

However, the Embarrassing Bodies team approached us one day, wanting to know if we had any 'serious cases' for their cancer programme. The team impressed us with their professionalism. I introduced Josh, a remarkable young man who had received life-saving surgery for a malignant myeloma of his orbit by consultant surgeons Mr David Verity and Professor Iain Hutchison. Josh was, and is, evangelical about the treatment he received. I believe that appearing on the programme was an affirmative and cathartic concluding episode to his ordeal.

We provided an immediately loaded fixed implant bridge into his scapulafree flap during the course of the programme, showing just how much can be done to improve quality of life for oral cancer victims.
Recently there has been a call in the $B D J$ for free dental care for patients suffering from mouth cancer $^{1}$ - what are your views on this?

Dental care for those patients suffering from mouth cancer is an essential part of getting their lives back together, preventing further dental problems, and of course, also picking up recurrence. Free local treatment and access to specialist dental services makes sense in every respect. Of course better for the patient, but also probably reducing the overall burden on the hospital service, with happier more confident and self-assured patients able to return to normality.

1. Trivedy $C$, Carter N. Unfairness for mouth cancer patients. Br Dent J 2012; 212: 3 .

Interview by Ruth Doherty, $B D J$ Managing Editor

Andrew Dawood and Susan Tanner are speaking on 'Restoring implants in practice - the scope of implant dentistry' on Thursday 25 April at the 2013 British Dental Conference \& Exhibition, which will take place in ExCeL, London. To register visit www. bda.org/conference. 